\title{
Axonal Regeneration and Physiological Activity Following Transection and Immunological Disruption of Myelin within the Hatchling Chick Spinal Cord
}

\author{
Hans S. Keirstead, ${ }^{1}$ Jason K. Dyer, ${ }^{1}$ Gerald N. Sholomenko, ${ }^{2}$ John McGraw, ${ }^{1}$ Kerry R. Delaney, ${ }^{2}$ and John D. \\ Steeves ${ }^{1}$ \\ 'Departments of Zoology, Anatomy, and Surgery, University of British Columbia, Vancouver, British Columbia, \\ Canada V6T $1 Z 4$ and 'Department of Biological Sciences, Simon Fraser University, Burnaby, British Columbia, \\ Canada V5A 1 S6
}

Transections of the chicken spinal cord after the developmental onset of myelination at embryonic day (E) 13 results in little or no functional regeneration. However, intraspinal injection of serum complement proteins with complementbinding GalC or 04 antibodies between E9-E12 results in a delay of the onset of myelination until E17. A subsequent transection of the spinal cord as late as E15 (i.e., during the normal restrictive period for repair) results in neuroanatomical regeneration and functional recovery. Utilizing a similar immunological protocol, we evoked a transient alteration of myelin structure in the posthatching $(P)$ chicken spinal cord, characterized by widespread "unravelling" of myelin sheaths and a loss of MBP immunoreactivity (myelin disruption). Myelin repair began within $7 \mathrm{~d}$ of cessation of the myelin disruption protocol. Long term disruption of thoracic spinal cord myelin was initiated after a P2-P10 thoracic transection and maintained for $>14 \mathrm{~d}$ by intraspinal infusion of serum complement proteins plus complement-binding GalC or 04 antibodies. Fourteen to $28 \mathrm{~d}$ later, retrograde tract tracing experiments, including double-labeling protocols, indicated that approximately $6-19 \%$ of the brainstem-spinal projections had regenerated across the transection site to lumbar levels. Even though voluntary locomotion was not observed after recovery, focal electrical stimulation of identified brainstem locomotor regions evoked peripheral nerve activity in paralyzed preparations, as well as leg muscle activity patterns typical of stepping in unparalyzed animals. This indicated that a transient alteration of myelin structure in the injured adult avian spinal cord facilitated brainstem-spinal axonal regrowth resulting in functional synaptogenesis with target neurons.

[Key words: spinal cord injury, regeneration, myelin

\footnotetext{
Received Oct. 20. 1994; revised June 9, 1995; accepted June 19, 1995.

We thank Karin Mathias, Ania Wisniewska, and Jason Bourque for their valuable technical assistance. Primary support for this study was provided by grants to J.D.S. from the Medical Research Council of Canada and the Canadian Neuroscience Network; additional support was provided by a grant to K.R.D. from the Natural Sciences and Engineering Research Council (NSERC) of Canada. H.S.K. was supported by scholarships from NSERC and the Neuroscience Network. J.K.D. is also a trainee of the Neuroscience Network. G.N.S. and J.K.D. were supported by postdoctoral fellowships from the Rick Hansen Man in Motion Legacy Foundation.

Correspondence should be addressed to John D. Steeves, Biological Sciences Building, UBC, 6270 University Boulevard, Vancouver, BC, V6T 1Z4 Canada. Copyright (C) 1995 Society for Neuroscience 0270-6474/95/156963-12\$05.00/0
}

sheath, myelin compaction, CNS, oligodendrocyte, galactocerebroside (GalC), 04 antibody]

Myelin-associated proteins have recently been identified that inhibit neurite outgrowth in vitro (Schwab and Caroni, 1988; McKerracher et al., 1994; Mukhopadhyay et al., 1994) and in vivo (Schnell and Schwab, 1990). We have also reported that myelin within the embryonic chick spinal cord inhibits functional regeneration of axotomized brainstem-spinal projections concerned with locomotion (Keirstead et al., 1992). Based on several myelin-specific markers (e.g., myelin basic protein, MBP; proteolipid protein, PLP; 2',3'-cyclic nucleotide $3^{\prime}$-phosphodiesterase, CNP; myelin associated glycoprotein, MAG; and luxol fast blue), the development of myelin within the chick spinal cord begins on embryonic day (E) 13 and is completed prior to hatching (Bensted et al., 1957; Hartman et al., 1979; Macklin and Weill, 1985; Keirstead et al., 1992, unpublished observations). The embryonic chick will functionally regenerate brainstem-spinal axons if transected prior to the developmental onset of myelination (Shimizu et al., 1990; Hasan ct al., 1991, 1993; Keirstead et al., 1992; Steeves et al., 1994).

In order to test the in vivo inhibitory properties of CNS myelin, we used an immunological method for delaying the onset of myelination until later stages of embryonic development (Keirstead et al., 1992). Spinal cord transections on embryonic day (E) 15 in myelin-suppressed animals resulted in significant neuroanatomical regeneration and complete functional recovery (Keirstead et al., 1992). Conversely, spinal cord transections on E15 in normally developing animals resulted in no repair whatsoever, rendering the animal incapable of voluntary locomotion after hatching. This study confirmed previous in vivo findings that myelin is inhibitory to the neuroanatomical regeneration of CNS axons (Schnell and Schwab, 1990). It also extended the results of Schwab and colleagues by demonstrating that myelin suppression could also facilitate functional recovery after CNS injury. Finally, it suggested that demyelination of the hatchling (i.e., adult) spinal cord might also facilitate repair following transection.

In the present study we observed that a similar immunological treatment does not result in demyelination, but instead produces a severe alteration of myelin structure within the hatchling chicken spinal cord (myelin disruption). We have used ultrastructural, immunohistochemical, retrograde tract tracing and electrophysiological methods to determine whether immunolog- 
ical myelin disruption facilitates axonal regeneration and physiological recovery by providing a more permissive extraneuronal environment for regenerating brainstem-spinal projections.

\section{Materials and Methods}

Fertilized White Leghorn eggs were incubated at $37^{\circ} \mathrm{C}$ in an automatic rotating incubator. After hatching, the quality of locomotion and general health of each animal was assessed. Only healthy animals with normal locomotor capabilities were included in the following experiments.

Spinal cord transection. Birds between the ages of posthatching day (P) 2 and P10 were anesthetized with an intramuscular injection of ketamine hydrochloride $(30 \mathrm{mg} / \mathrm{kg}$ ) plus xylazine (Rompun, $3 \mathrm{mg} / \mathrm{kg}$ ). After removal of one dorsal process of the fused avian vertebral column overlying the mid thoracic spinal cord, the spinal cord was transected using a sharpened corneal blade (Fine Science Tools, North Vancouver, British Columbia) of $3.0 \mathrm{~mm}$ in diameter, equivalent to the inside diameter of the hatchling chick vertebral column. The corneal blade was inserted transversely through the spinal cord to the inner ventral surface of the spinal column and rotated from side to side until the entire cord was severed. Where the effect of spinal cord myelin disruption on neuronal repair was being examined, the immunological myelin disruption protocol was initiated (within $1 \mathrm{hr}$ ) during the same surgical procedure, but always after the spinal cord transection (for details see below).

To ensure complete transection of the spinal cord, hatchling chicks were randomly selected immediately after transection and their spinal cords fresh-dissected and examined under a dissecting microscope. In addition, some hatchling chicks received low thoracic injections of 0.5 $\mu l$ of tetramethylrhodamine-labeled dextran amine (RDA; see "neuroanatomy" below) at the time of thoracic spinal cord transection. These control animals were perfused intracardially $21 \mathrm{~d}$ later with $0.1 \mathrm{M}$ PBS containing 2500 USP units of heparin per $50 \mathrm{ml} \mathrm{PBS}$, pH 7.4 (at $37^{\circ} \mathrm{C}$ ) followed by perfusion with $4 \%$ paraformaldehyde in $0.1 \mathrm{M}$ phosphate buffer, $\mathrm{pH} 7.4$ (at $4-10^{\circ} \mathrm{C}$ ). Other control animals received lumbar injections of $0.5 \mu \mathrm{l}$ of RDA $17 \mathrm{~d}$ after thoracic spinal cord transection; $48 \mathrm{hr}$ later, they were perfused as outlined above. Brainstem and spinal cord tissue were then postfixed for $24 \mathrm{hr}$ at $4^{\circ} \mathrm{C}$. The dissected brainstems were transferred to $30 \%$ sucrose in $0.1 \mathrm{M} \mathrm{PBS}, \mathrm{pH} 9.0\left(4^{\circ} \mathrm{C}\right)$ for $24 \mathrm{hr}$. Each brainstem was sectioned in the transverse plane using a Leitz liquid $\mathrm{CO}_{2}$ freezing microtome and examined for the presence of RDA retrograde-labeling of brainstem-spinal neurons. The dissected spinal cords were subsequently embedded in paraffin according to standard protocols. Parasagittal $10 \mu \mathrm{m}$ sections were cut and examined for evidence of the injection site and extent of the transection.

Transient immunological myelin disruption. Transient immunological myelin disruption was performed on two groups of experimental animals; the first to characterize myelin disruption alone and the second to evaluate the effect of myelin disruption on neuronal repair after a spinal cord transection. Birds between the ages of P2 and P10 were anesthetized with an intramuscular injection of ketamine hydrochloride ( $30 \mathrm{mg} / \mathrm{kg}$ ) plus xylazine (Rompun, $3 \mathrm{mg} / \mathrm{kg}$ ). After removal of one dorsal process of the fused avian vertebral column overlying the mid thoracic spinal cord, direct spinal cord injections were performed using a glass micropipette (tip diameter $=30-40 \mu \mathrm{m} ; \mathrm{A}-\mathrm{M}$ Systems, Everett, WA \#6045) connected to a Picospritzer ll pressure injection system (General Valve Corp., Fairfield, NJ). Each animal received a total volume of $10 \mu \mathrm{l}$, over one to four penetrations of the mid thoracic cord. Alternatively, solution was delivered over longer time periods by inserting into the exposed low thoracic spinal cord a canula connected to a $7 \mathrm{~d}$ (model \#1007D) or $14 \mathrm{~d}$ (model \#2ML2) osmotic mini-pump (Alzet Corp., Palo Alto, CA) which was then placed under the skin on the dorsal surface of the neck. The osmotic pumps used in these experiments deliver solution at a rate of $0.5 \mu \mathrm{l}$ per hour, or $12 \mu \mathrm{l}$ per day. Immunological myelin disruption in hatchling chicks was evoked with either an $\mathrm{IgG}_{1}$ polyclonal GalC antibody (Chemicon International Inc., Temecula, California \#AB 142) at a dilution of 1:5 with $33 \%$ guinea pig complement (GIBCO BRL, Burlington, Ontario \#19195-015) in $0.1 \mathrm{M}$ phosphate-buffered saline (PBS), pH 7.4 or an IgM polyclonal 04 antibody (a gift from Melitta Schachner, Swiss Federal Institute of Technology) at a dilution of $1: 5$ with $33 \%$ guinea pig complement (GIBCO $\mathrm{BRL}$ ) in $0.1 \mathrm{M}$ PBS pH 7.4. Immunological controls consisted of either: (1) guinea pig serum complement proteins only, (2) GalC antibody only, (3) 04 antibody only, or (4) vehicle only (0.1 M PBS, pH 7.4). These immunological control solutions were delivered by direct spinal cord injection or by osmotic pump, as outlined above. In those animals un- dergoing both transection and immunological myelin distuption, the site of the infusion canula was two segments $(3-5 \mathrm{~mm}$ ) caudal to the transection site and always inserted during the hour following after transection.

To assess the onset of spinal cord myelin disruption, the duration of the myelin disruption and the degree of myelin recovery, hatchling chicks were perfused at appropriate intervals (see results) as outlined above. Spinal cord tissue sections were processed for immunohistochemistry or electron microscopy as outlined below.

Electron microscopy. Tissue for electron microscopy was obtained from animals sacrificed $5 \mathrm{~d}$ after installation of a $7 \mathrm{~d}$ osmotic pump. Animals were deeply anaesthetized and perfused intracardially at the appropriate stage (see Results) with $0.1 \mathrm{M}$ phosphate-buffered saline (PBS) containing $2500 \mathrm{USP}$ units of heparin per $50 \mathrm{ml} \mathrm{PBS}, \mathrm{pH} 7.4$ (at $37^{\circ} \mathrm{C}$ ), followed by $4 \%$ paraformaldyhyde in PBS (ice cooled) and postfixed overnight in the same fixative. Small tissue blocks were transferred to $2.5 \%$ glutaraldehyde in $0.1 \mathrm{M}$ phosphate buffer, $\mathrm{pH} 7.4$ (at 4 $10^{\circ} \mathrm{C}$ ), for $12 \mathrm{hr}$. The dissected tissue was then washed in $0.2 \mathrm{M}$ sodium cacodylate buffer $(24 \mathrm{hr})$, osmicated, dehydrated and embedded in Spurrs resin according to standard protocols. Control and experimental animals were processed in parallel. Thin sections were cut at $100 \mathrm{~nm}$, mounted on copper grids, uranyl acetate and lead citrate stained and viewed under a Ziess EM $10 \mathrm{C}$ electron microscope (at $80 \mathrm{kV}$ ) at a Illagnification of $10,000 \times$.

Immunohistochemistry. Antigens were localized using indirect immunofluorescence. GalC immunohistochemistry was performed on cryostat-sectioned tissue. All other antigens were localized on paraffinembedded tissue sections. The rabbit anti-human myelin basic protein antibody (MBP; Accurate Chemical Scientific Corp., \#AXL746) and the rabbit anti-cow glial fibrillary acidic protein (GFAP; Dakopatts Corp., \#Z334) were used at a dilution of $1: 100$ in $1 \%$ goat serum in PBS containing 3\% Triton X-100. The rabbit anti-bovine GalC antibody (Chemicon $\mathrm{AB}$ 142) was used at a dilution of $1: 10$ in $1 \%$ goat serum in PBS containing 3\% Triton X-100. The secondary antibody was a goat anti-rabbit FITC conjugated immunoglobulin (Caltag Laboratories, \#L42001) diluted 1:100 or a goat anti-mouse FITC conjugated immunoglobulin (Dimension Labs, \#30112663) diluted 1:100 in 1\% goat serum in PBS containing 3\% Triton $\mathrm{X}-100$.

Standard immunocytochemical controls (e.g., omission of primary and/or secondary antibodies) were processed alongside tissue sections from experimental and control animals. Preadsorption controls were conducted by the respective supplier of each antibody. Photomicrographs were taken on a 7eiss Axiophot using epifluorescent illumination with appropriate filters.

Retrograde tract tracing. Birds were anesthetized $14-28 \mathrm{~d}$ after spinal cord transection and immunological myclin disruption with an intramuscular injection of ketamine hydrochloride $(30 \mathrm{mg} / \mathrm{kg}$ ) plus xylazine (Rompun, $3 \mathrm{mg} / \mathrm{kg}$ ). One dorsal process of the fused avian vertebral column overlying the low thoracic spinal cord (approximately 8 $\mathrm{mm}$ caudal to the previous transection site) was then removed; $0.2-0.5$ $\mu \mathrm{l}$ of $25 \%$ tetramethylrhodamine-labeled dextran amine (RDA; Molecular Probes Inc., Eugene, Oregon, $10000 \mathrm{MW}$, \#D-1817) or $0.2-0.5 \mu 1$ 25\% cascade blue-labeled dextran amine (CBDA; Molecular Probes Inc., Eugene, OR, 10,000 MW, \#D-1976) in $2.5 \%$ Triton X-100 diluted in $0.1 \mathrm{M}$ Tris-buffer ( $\mathrm{pH} \mathrm{9.0)}$ was directly injected into the spinal cord using a glass micropipette (tip diameter $=40-50 \mu \mathrm{m}$ ) connected to a Picospritzer 11 pressure injection system. Previous studies indicated that this volume of RDA or CBDA remains confined to the spinal cord injection site (i.e., does not diffuse rostrally to, or above, the site of transection) and within $24-48 \mathrm{hr}$ is retrogradely transported via brainstem-spinal axons to the cell bodies of origin, with no transsynaptic transport to brainstem neurons not having spinal projections (Hasan et al., 1991; Keirstead et al., 1992; Hasan et al., 1993). After $48 \mathrm{hr}$, the birds were given a lethal intramuscular injection of anesthetic (sodium pentobarbital, $75 \mathrm{mg} / \mathrm{kg}$ ) and then perfused and fixed, with the brainstem and spinal cord tissue processed as outlined above.

Electrophysiological stimulation and recording. Birds were anesthetized 15-24 d after spinal cord transection and immunological myelin disruption with an intramuscular injection of ketamine hydrochloride (30 $\mathrm{mg} / \mathrm{kg}$ ) plus xylazine (Rompun, $3 \mathrm{mg} / \mathrm{kg}$ ). The head was placed in a stereotaxic head holder and the calvarium and dura mater resected. The cerebral hemispheres and diencephalon were then removed by dissection (i.e., a decerebration; for details, see Hasan et al., 1991, 1993) and anesthesia was discontinued.

Bipolar hook electrodes were implanted in the sartorius (SART) mus- 

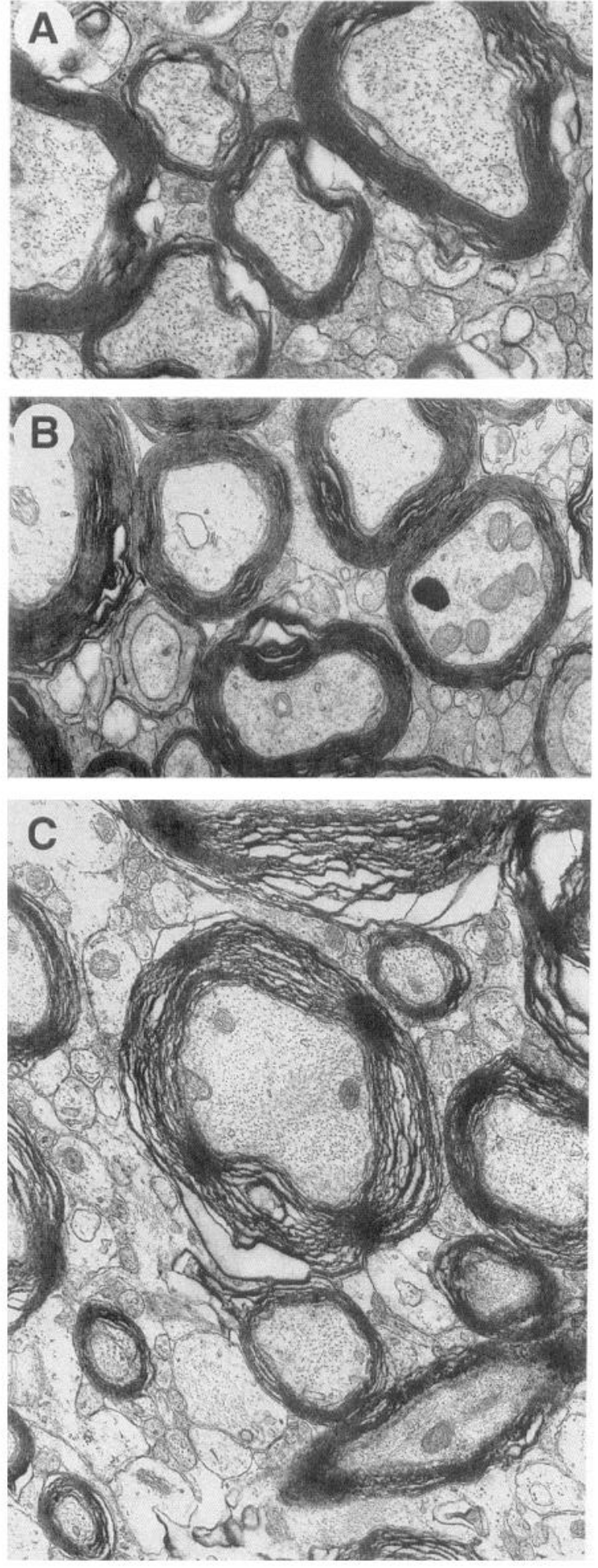

Figure 1. Electron photomicrographs of myelin morphology within hatchling spinal cord. $A$, Untreated normal spinal cord showing normal pattern of myelination within mature spinal cord. $B$, Control injected (injected with serum complement proteins alone) showing a similar mylein morphology to untreated control spinal tissue. In short, myelin wraps are highly compacted, with no evidence of cellular disruption. $C$, Myelin disruption after intraspinal injection with serum complement proteins and anti-galactocerebroside antibodies. Disruption included enlargment of the periaxonal space, as well as separation of the myelin lamellae. Some short regions of the myelin sheath retain a compacted appearance. Some of the myelin around a few small diameter axons cle of each leg and each pectoralis (PECT) muscles of each wing. The SART acts as a strong hip flexor and weak knee extensor (Hasan et al., 1993). The PECT acts as a major wing depressor (Hasan et al., 1993). Electromyographic (EMG) muscle activity was amplified (1000X), bandpass filtered $(100-1000 \mathrm{~Hz})$ and recorded on video tape and an electrostatic chart recorder. Subsequent to the EMG recording, the SART and PECT nerves were exposed and bipolar electrodes were hooked onto each nerve. The animal was paralyzed with flaxadil (gallamine triethoiodide, $1.0 \mathrm{mg} / \mathrm{kg}$ ) and unidirectionally ventilated (for details, see Sholomenko et al., 1991). Electroneurographic (ENG) nerve activity was amplified $(1000 \times)$, bandpass filtered $(100-5000 \mathrm{~Hz})$, and recorded on videotape and an electrostatic chart recorder.

Brainstem regions within the ventromedial mesencephalic, pontine and medullary reticular formation were serially probed with a monopolar stimulating electrode. Stimulation was in the form of alternating square wave monophasic pulses (pulse duration $=0.5 \mathrm{msec}$ ) at $30 \mathrm{~Hz}$. Electrical current strengths varied from 10 to $300 \mu \mathrm{A}$. When a stimulation trial evoked locomotion (wing and/or leg), the lowest effective stimulation strength (threshold) was subsequently determined and evoked locomotor EMG or ENG patterns were then recorded. Following stimulation trials, effective brainstem stimulation sites were marked by making a small electrolytic lesion $(1 \mathrm{~mA} \mathrm{DC}$ for $5 \mathrm{sec})$. The hatchling chick was then perfused as outlined above. Standard histological techniques were used for preparation of brainstem tissue sections.

\section{Results}

Transient immunological myelin disruption and myelin recovery

The transient disruption of spinal cord myelin in the hatchling chick was achieved by infusing an immunological "cocktail" directly into the low thoracic spinal cord between P2 and P10. The immunological cocktail consisted of serum complement proteins plus a myelin/oligodendrocyte-specific, complementbinding antibody. Polyclonal galactocerebroside (GalC) antibody and polyclonal 04 antibody are myelin/oligodendrocyte-specific, complement-binding antibodies (Ranscht et al., 1982; Sommer and Schachner, 1982). The subsequent state of spinal cord myelin within both experimental and control animals was assessed with myelin basic protein (MBP) immunohistochemistry and electron microscopy. When either of the antibodies was combined with guinea pig serum complement proteins and injected or infused into the spinal cord, it usually caused rapid myelin disruption within the spinal cord. In 45 of 69 animals examined (60 animals with single intraspinal injections and 9 animals with $7 \mathrm{~d}$ osmotic pumps), a loss of MBP immunoreactivity extended over the entire cross-sectional area of the cord. The average rostrocaudal extent of myelin disruption was 12 spinal cord segments (range 2-22 segments), with an equivalent number of segments exhibiting a loss of immunoreactivity in either direction from the site of injection. In 14 of 69 animals, the loss of MBP immunoreactivity was more prominent on one side of the cord and in 2 animals there was a distinctly separate region exhibiting a loss of MBP immunoreactivity in the cervical spinal cord.

Electron microscopic examination of five spinal cords exhibiting a loss of MBP immunoreactivity revealed a significant structural alteration of inner and outer myelin lamellae. The myelin disruption protocol resulted in "unravelling" of myelin la-

$\leftarrow$

appears unaffected by the immunological treatment, their associated myelin wraps remaining intact. On other pictures, oligodendrocytes are visible, appearing normal, with no significant astroglial or mononuclear phagocytotic response being observed. The normal appearance of cellular organelles and the disruption of myelin around both small and large diameter axons suggests that immunologically induced myelin disruption was not an artifact of tissue preparation. Original magnification for all photographs was $10,000 \times$. 
mella, and a separation of the myelin sheath from the axon (Fig. 1). Myelin disruption was most evident around large diameter axons. However, the myelin lamellae of small diameter axons were similarly affected although many small diameter myelin sheaths appeared unperturbed within the area of myelin disruption. Oligodendrocyte cell bodies were identified by their morphology within the area of myelin disruption, suggesting that oligodendrocyte cell bodies survive the myelin disruption protocol. Astrocytes were also identified by their morphology within the area of myelin disruption, and did not appear to be hypertrophic. Ultrastructural analysis indicated only a few macrophages containing myelin debris within the area of myelin disruption.

The extent and degree of spinal cord myelin disruption was similar whether the procedure involved a single intraspinal injection or via infusion with an osmotic pump; the only apparent difference was the duration of myelin disruption (see below). The extent and degree of spinal cord myelin disruption was similar when the immunological protocol was initiated on either P2, P3, P4, P5, P6, P7, P8, or P10 (Fig. 2). Approximately one-half of the spinal cords contained occasional "clumps" of MBP immunoreactivity, indicative of myelin debris, distributed randomly throughout the zone of myelin disruption (Fig. $2 C$ ). There were no noticeable differences in the behaviors of any experimental animals when compared to normally myelinated control animals; nor were any pathological conditions noted.

On P6, hatchlings used as immunological controls were administered either: (1) guinea pig complement only $(n=12),(2)$ GalC antibody only $(n-12)$, (3) 04 antibody only $(n-12)$, or (4) vehicle only ( $0.1 \mathrm{M}$ PBS, $\mathrm{pH} 7.4 ; n=12)$ on P6. From each group of immunological control hatchlings, four animals were sacrificed 1,5 , and $12 \mathrm{~d}$ after the beginning of each treatment. MBP immunohistochemistry and ultrastructural analysis of their spinal cords revealed no evidence for myelin disruption (Figs. $1 B, 2 D$ ). Histological examination did not reveal any tissue damage.

Using MBP immunohistochemical staining as an indicator of myelin integrity, the onset and duration of immunological myelin disruption (without an accompanying transection) was examined. Single micropipette injections of complement plus a myelin/oligodendrocyte-specific antibody into the spinal cord were performed on a total of 102 hatchling chicks (91 animals with complement plus GalC antibody and 11 animals with complement plus 04 antibody). There was no evidence of immunological myelin disruption at 6 or $9 \mathrm{hr}(n=4$ for each time) after the onset of the immunological protocol, however, myelin disruption was evident $12 \mathrm{hr}$ after injection, in 4 of 5 animals examined. After 1 or $2 \mathrm{~d}$, immunological myelin disruption was evident in the majority of cases (38 of 47 animals, including all 8 chicks treated with complement plus 04 ). Three days after a single intraspinal injection, 20 of 31 animals still exhibited myelin disruption, including all $3 \mathrm{O} 4$ treated chicks. Based on MBP immunofluorescence in 11 chicks, myelin disruption did not appear to be maintained for longer than $3 \mathrm{~d}$ after a single injection (ie. the myelin disruption was transient).

Long-term infusion, using 7 or $14 \mathrm{~d}$ osmotic pumps, of complement plus GalC antibody into the spinal cord was examined in 23 hatchlings. On the basis of MBP immunohistochemistry, toluidine blue staining (not shown), and electron microscopy, immunological myelin disruption was clearly evident in all five animals sacrificed $5 \mathrm{~d}$ after installation of a $7 \mathrm{~d}$ osmotic pump. Immunohistochemical evidence for myelin disruption was still evident in all four animals sacrificed $12 \mathrm{~d}$ after installation of a $14 \mathrm{~d}$ pump. No evidence of immunological myelin disruption was detected in all six animals sacrificed $21 \mathrm{~d}$, and all eight animals sacrificed $24 \mathrm{~d}$, after installation of a $14 \mathrm{~d}$ pump, suggesting that the myelin disruption was transient and did not persist for a substantial duration beyond the infusion period. In summary, the immunological protocol appeared to disrupt myelin within $12 \mathrm{hr}$ of infusion and persist throughout the entire infusion period.

Oligodendrocytes and astrocytes appeared to be unaffected by the immunological myelin disruption protocol. Using ultrastructural analysis, Oligodendrocyte cell bodies were identified by their morphology within the region of myelin disruption. The similarity in the immunoreactivity for GalC in unoperated control $(n=3)$ and myelin disrupted $(n=3)$ hatchling chick spinal cords indicated that oligodendrocyte cell bodies survived the immunological protocol (Fig. $3 A, B$ ). GalC is present on the surface of oligodendrocyte and myelin membranes (Ranscht et al., 1982). Immunological myelin disruption was confirmed in experimental animals by a lack of MBP immunoreactivity. The spinal astrocyte population was assessed by glial fibrillary acidic protein (GFAP) immunohistochemistry. The astrocyte number and distribution in immunologically myelin disrupted spinal cords (Fig. $3 D$ ) was similar to that of unoperated age-matched control tissue ( $n=8$; Fig. $3 C$ ). Immunohistochemical analysis of spinal cords from animals sacrificed $1 \mathrm{~d}(n=3), 4 \mathrm{~d}(n=$ $2)$ and $5 \mathrm{~d}(n=2)$ after the injection of complement proteins and GalC antibodies on $\mathrm{P} 2$ revealed no evidence of astrogliosis. Similar findings were noted for animals examined $1 \mathrm{~d}$ after injection of serum complement proteins and GalC antibodies on P5 $(n=3)$. Additionally, individual astrocytes in myelin disrupted spinal cords did not have a hypertrophic appearance or qualitatively express higher levels of GFAP than individual astrocytes from unoperated control tissue at the same age.

Direct pressure injection of control and experimental solutions into the thoracic spinal cord did not result in significant damage to the spinal cord tissue. The injected solution did not noticeably displace spinal cord tissue or result in a region of necrosis at the injection site. Likewise, canula insertion into the spinal cord was not followed by necrosis or cavity formation. Three weeks after pump installation, the hole in the spinal cord initially created by the canula did not exceed the diameter of the canula itself (results not shown).

\section{Spinal transection controls}

As previously noted in embryonic chicks (Hasan et al. 1991,1993; Keirstead, 1992), and in contrast to mammals, severing the hatchling chick spinal cord did not result in the formation of a cavity or cyst at or near the site of transection. Of 43 spinal cords examined, 15-24 d after a complete transection, the proximal and distal segments were intimately juxtaposed at the transection site. Autofluorescent inflammatory infiltrates at the transection site were minimal. To ensure complete transection of the spinal cord, 12 hatchling chicks were randomly selected immediately after transection, dissected, and examined under a microscope. In all cases a complete spinal cord transection was confirmed.

In addition, six animals received a lumbar injection of RDA at the time of thoracic spinal cord transection. Only a complete spinal cord transection would prevent the retrograde axonal transport of this tracer to the cell bodies of origin in the brainstem. Twenty-one (21) days after transection and RDA injection, 

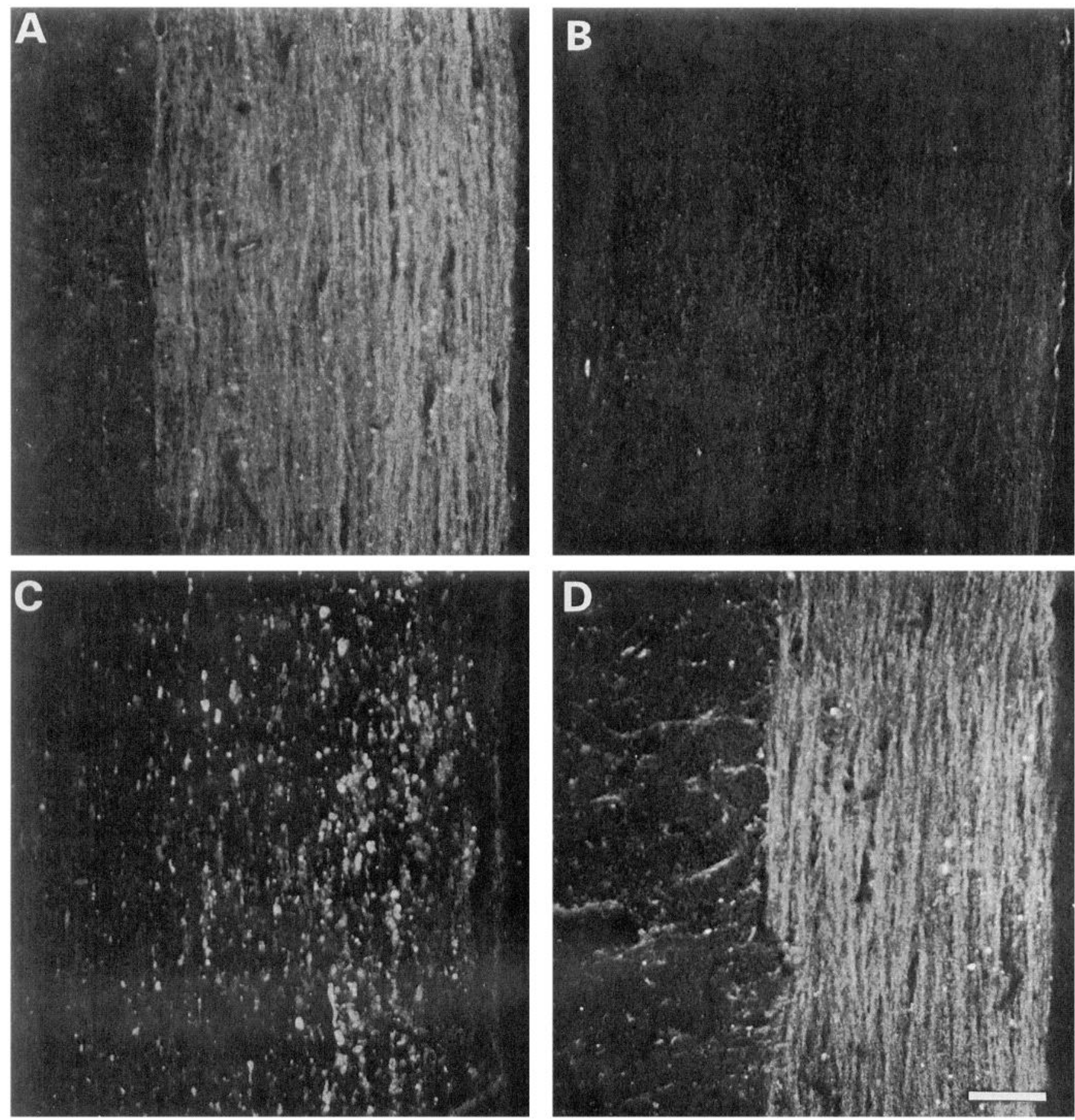

Figure 2. Immunological myelin disruption in the thoracic spinal cord of the hatchling chick in parasagittal section (white matter on right side of all figures). A, Unoperated (normally myelinated) control posthatching day (P) 2 chick showing extensive myelin basic protein (MBP) immunoreactivity within the spinal cord white matter. Spinal cord myelination is complete prior to hatching and remains relatively unchanged thereafter. $B$, MBP immunofluorescence staining of a P7 hatchling spinal cord $24 \mathrm{hr}$ after a single intraspinal injection of serum complement with galactocerebroside $(\mathrm{GalC})$ antibodies; note the absence of immunoreactivity. $C$, MBP immunofluorescence staining of a P7 spinal cord $24 \mathrm{hr}$ after a single intraspinal injection of complement with GalC antibodies; note the presence of MBP immunoreactive "clumps" characteristic of myelin debris. $D$, MBP immunofluorescence staining of a P7 spinal cord $24 \mathrm{hr}$ after a single intraspinal injection of GalC antibodies alone; note that myelin is unperturbed and comparable to $A$. Myelin disruption was not evident after the injection of complement alone, or PBS vehicle alone. In all photographs the outer edge of the spinal cord lies on the right hand side, with the white matter immediately adjacent. Scale bar, $100 \mu \mathrm{m}$.

these animals were sacrificed and their brains examined for the presence of retrograde-labeled brainstem-spinal neurons. In no case was there any evidence of retrograde transport of RDA to the brainstem (results not shown), confirming that the transection was complete. In all cases analysis of the spinal cords only revealed RDA-labeled cells caudal to the transection site, but no evidence of RDA transport to any region of the spinal cord rostral to the transection site. 

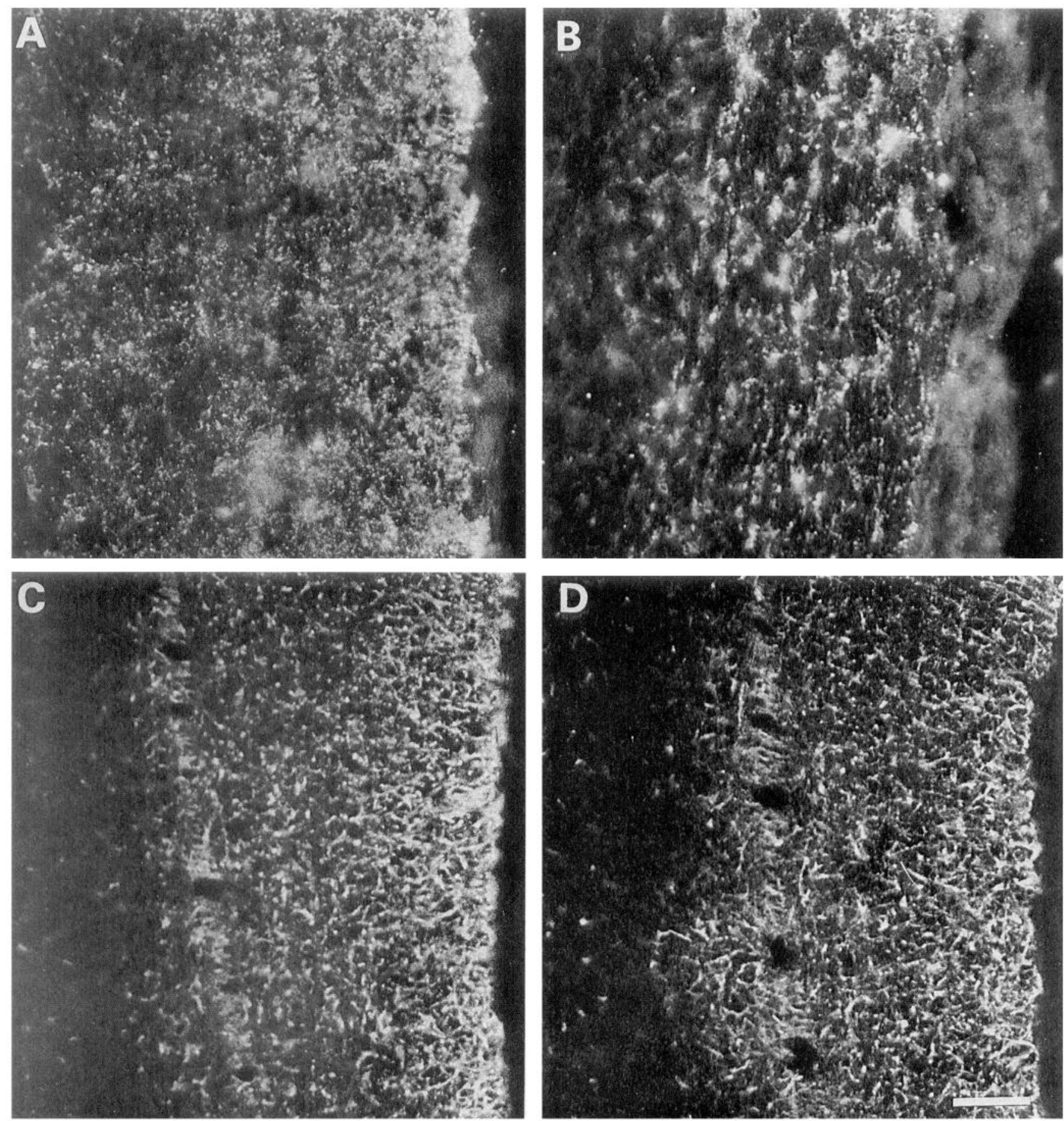

Figure 3. Patterns of GalC and glial fibrillary acidic protein (GFAP) immunoreactivity during immunological myelin disruption (white matter on right side of all figures). A, Unoperated (normally myelinated) control P7 spinal cord showing GalC immunoreactivity within the white matter. GalC is localized in both oligodendrocyte and myelin membranes. B, GalC immunofluorescence staining of a P7 spinal cord $24 \mathrm{hr}$ after a single intraspinal injection of serum complement with $\mathrm{GalC}$ antibodies; note that $\mathrm{GalC}$ immunoreactivity is reduced due to myelin disruption. $C$, Unoperated (normally myelinated) control P6 spinal cord showing extensive GFAP immunoreactivity within the white matter. GFAP reliably identifies astrocytes. $D$, GFAP immunofluorescence staining of a P6 spinal cord $24 \mathrm{hr}$ after a single intraspinal injection of serum complement with GalC antibodies; note that GFAP immunoreactivity is comparable to that observed in $C$, indicating that that the immunological protocol for myelin disruption does not appear to change the state of astrocytes. Scale bar, $100 \mu \mathrm{m}$.

\section{Regeneration after spinal transection and transient myelin disruption}

Spinal cord transections and subsequent osmotic pump installations (containing either the experimental or control immuno- logical solutions) were successfully performed on a total of 48 hatchling chicks, ranging in ages from P2-P10. In all cases, experimental or control solutions were administered using a 14 d osmotic pump connected via catheter to a canula inserted two 
spinal cord segments caudal to the transection site. Retrograde tract tracing assessments of spinal cord axonal regeneration were conducted on all 48 of these animals. Electrophysiological assessments of spinal cord regeneration (in addition to neuroanatomical assessments) were conducted on eight of these animals. In all cases, the spinal cord transection preceded the osmotic mini-pump installation by $15-30 \mathrm{~min}$.

Axonal regeneration was assessed 14-28 d after spinal cord transection by counting the number of brainstem-spinal neurons labeled by the retrograde transport of RDA injected into the low thoracic spinal cord 12-26 d after transection (Fig. 4). The number of retrogradely labeled neurons counted within the reticular formation of age-matched, unoperated control hatchlings averaged $1043 \pm 53.3$ (number of retrogradely labeled neurons in each individual: $692,814,1034,1035,1040,1042,1045,1052$, $1130,1281,1311 ; n=11$; range $=692-1311$; Fig. $4 A$ ). In transected, myelin disrupted hatchling chicks the number of retrogradely labeled neurons within the reticular formation averaged $148 \pm 6.6$ (number of regenerated neurons in each individual: $71,98,116,131,136,136,137,141,141,144,148,149$, $149,157,162,164,166,181,189,191,202 ; n=21$; range = 71-202; Fig. $4 B$ ). This degree of axonal regeneration averaged $14 \%$ of control numbers (range $=6-19 \%$ ). Comparable ratios for regenerated neurons were also noted for several other brainstem-spinal nuclei with projections to the low thoracic and lumbar spinal cord (vestibular nucleus, locus ceruleus, subceruleus nucleus and raphe nucleus). For example, vestibulospinal axonal regeneration averaged $15 \%$ of controls (regenerated numbers: $221,278,299,320$, mean $=280 \pm 21.3$, or $15 \%$; control numbers: $1650,1711,1992,2100$, mean $=1863 \pm 108.5$; Fig. $4 C, D)$. Interestingly, rubrospinal axon regeneration was rarely obseved, however, rubrospinal projections primarily terminate at the cervical level (Webster and Steeves, 1988). The greatest amount of axonal regeneration was observed in animals that had been infused for $14 \mathrm{~d}$ with serum complement and the myelin/ oligodendrocyte-specific, complement binding antibody.

In contrast, transected hatchlings that were intraspinally infused with control solutions over a 2 week period showed no signs of neuroanatomical regeneration after 15-24 d of recovery (results not shown). No retrograde-labeled brainstem-spinal neurons were observed in transected hatchling chicks that were administered: (1) guinea pig complement only $(n=3)$, (2) polyclonal GalC only $(n=3)$, or (3) PBS vehicle only $(n=10)$.

All available evidence indicates that brainstem-spinal neurons have completed all their spinal projections prior to embryonic day 12 of development, approximately 2 weeks prior to transection (Okado and Oppenheim, 1985; Hasan et al., 1991, 1993). However, In order to ensure that the neuroanatomical recovery of transected, myelin disrupted hatchling chicks was indeed due to true axonal regeneration (and not neurogenesis and/or subsequent axonal development), a double labeling paradigm was adopled (for details see Hasan et al., 1993). On PG, a maximal number of brainstem-spinal projections was labeled with a low thoracic spinal cord injection of RDA. After $24 \mathrm{hr}$ to allow for retrograde transport of the first (RDA) retrograde tracer, the thoracic spinal cord was transected and a $14 \mathrm{~d}$ osmotic pump containing complement plus GalC antibodies was installed: The second retrograde tract tracer (cascade blue labeled dextran amine; CBDA) was injected into the low thoracic spinal cord $20 \mathrm{~d}$ later. Analysis of the brainstem revealed double-labeled neurons within several regions of the brainstem with projections to the thoracic and lumbar spinal cord including: the reticular formation, vestibular nucleus, locus ceruleus, subceruleus nucleus and raphe nucleus $(n=3$; Fig. $5 A, B)$. Less than 10 cells per nucleus were double labeled. Cells labeled exclusively by the first or the second tracer were present in every brainstem analysed. The low number of double labeled brainstem-spinal neurons may in part be due to the requirement that an axon must be severed or permeabilized with detergent for uptake and retrograde transport of fluorescent-conjugated dextran amine dye (cf. Heimer and RoBards, 1981; Hasan et al., 1993). Severing or permeabilizing the same brainstem-spinal axon during both retrograde tracer injection procedures could not be assured. Thus, these results are probably an underestimate, but definitely not an overestimate of the degree of brainstem-spinal regeneration after myelin disruption. Previous studies have indicated that, even in an untransected chick, the maximal number of double-labeled neurons obtainable from the intraspinal injection of two different retrograde tract tracers is $30 \%$ of the number labeled by either tracer alone (Hasan et al., 1993).

Prior to sacrifice, hatchling chicks that had undergone transection and myelin disruption did not show any voluntary signs of locomotor recovery. From the first day of recovery after spinal cord transection, all animals remained incapable of standing or supporting their weight. Spinal reflexes recovered within $1 \mathrm{~d}$ posttransection and all animals subsequently exhibited stretch, flexion and crossed-extension reflexes. Spontaneous alternating leg movements were often observed throughout the 15-24 d recovery period. A decrease in the size of leg muscles (i.e., disuse atrophy) was always observed.

More invasive physiological assessments of motor capabilities were then undertaken on a few transected and myelin disrupted hatchling chicks ( $n=3$, as well as control-treated (PBS alone or GalC alone) animals $(n=5)$. All of these animals were included in the neuroanatomical analysis outlined above. Three weeks after spinal cord transection and the initiation of immunological myelin disruption via a $14 \mathrm{~d}$ osmotic pump, focal stimulation of a brainstem locomotor region in a decerebrate, hatchling chick evoked rhythmic motor activity both above (pectoralis, PECT) and below the site of transection $(n=3)$. Electromyograms (EMG) from the sartorius muscles (SART; major hip flexor) exhibited alternating activity in the right and left legs (Fig. 6), typical of stepping movements. It is possible that brainstem-evoked wing movements might have contributed to generating the alternating leg activity observed. Therefore, following EMG recording, the animals were paralysed and unidirectionally ventilated to prevent all body movements (see Sholomenko et al., 1991). The effective current stimulation strength necessary to evoke activity within the SART nerve was higher, but bursting activity could still be obtained during each subsequent brainstem stimulation trial (results not shown). Nevertheless, the pattern of evoked SART nerve activity in paralysed preparations was not characteristic of stepping. The change between SART muscle and nerve activity patterns could be due to one or more differences between unparalysed and paralysed states, not the least of which is the lack of rhythmic sensory feedback in paralyzed preparations. In transected control animals, treated with GalC only $(n=2)$ or PBS only $(n=3)$, focal stimulation of brainstem locomotor regions resulted in rhythmic, in phase PECT activity above the transection site (i.e., wing flapping), but no evoked EMG or nerve activity was present below the transection site. 

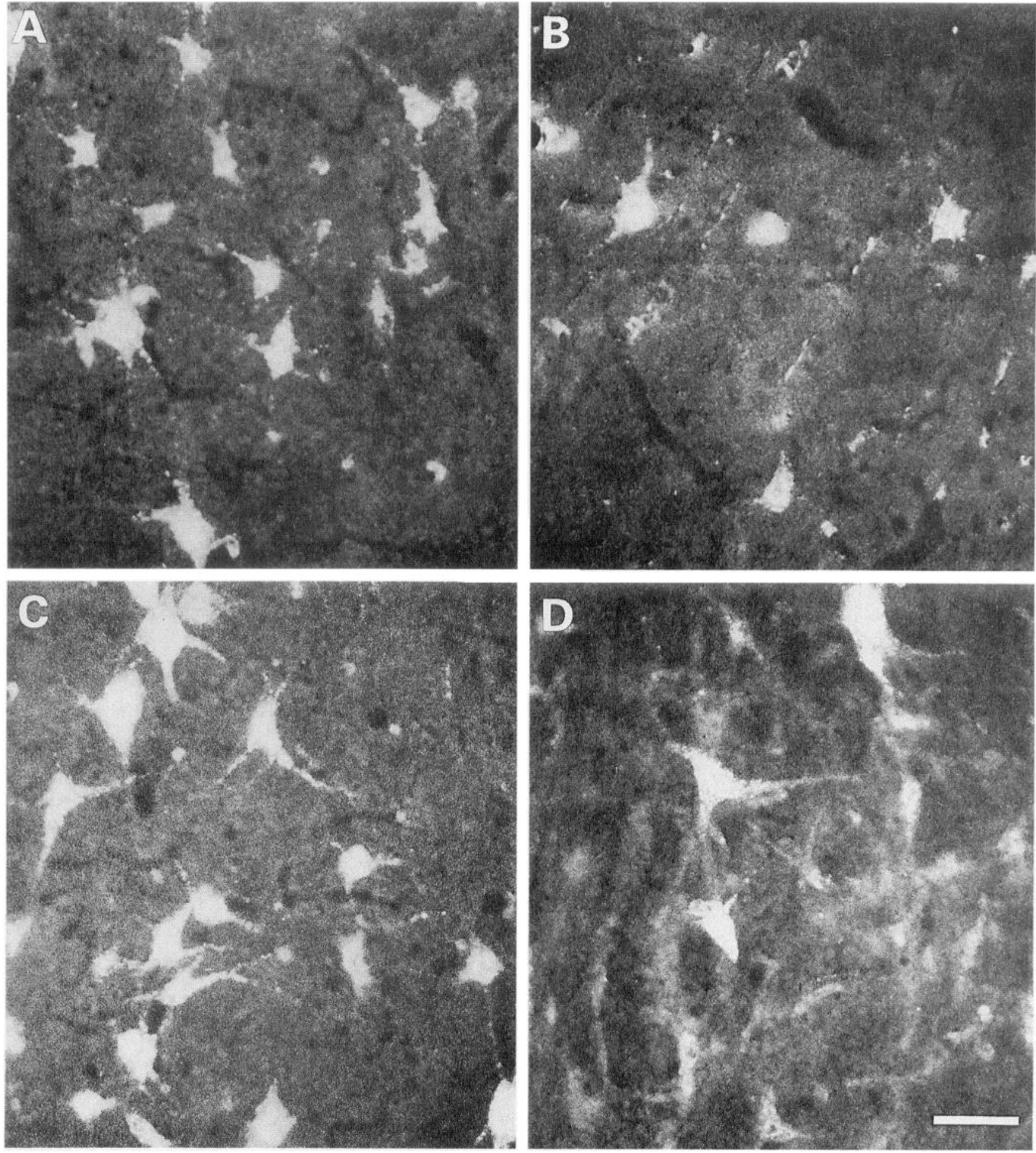

Figure 4. Neuroanatomical regeneration of brainstem-spinal projections after transection and immunological myelin disruption of the hatchling thoracic spinal cord. Photomicrographs of retrograde-labeled neurons within the brainstem in P28 chicks. Brainstem-spinal neurons were labeled by the retrograde axonal transport of tetramethylrhodamine-labeled dextran amine (RDA) injected into the lumbar spinal cord on P26 and allowed $2 \mathrm{~d}$ for transport. $A$, Retrogradely labeled gigantocellular reticulospinal neurons within the ventromedial reticular formation of the caudal pons in an unoperated (normally myelinated) control P28 chick. B, Retrogradely labeled gigantocellular reticulospinal neurons within the ventromedial reticular formation of the caudal pons in a P28 hatchling chick $24 \mathrm{~d}$ after thoracic transection and immunological myelin disruption; note the number of retrogradely labeled neurons is less than $A$. $C$, Retrograde-labeled vestibulospinal neurons within the lateral vestibular nucleus of the dorsolateral pons in an unoperated (normally myelinated) control P28 chick. $D$, Retrogradely labeled vestibulospinal neurons within the lateral vestibular nucleus of the dorsolateral pons in a P28 hatchling $24 \mathrm{~d}$ after transection and immunological myelin disruption; note the number of retrograde-labeled neurons is less than $C$. The percentage of retrogradely labeled brainstem-spinal neurons in transected, myelin disrupted hatchling chicks averaged $14 \%$ (range 6-19\%) of controls. Comparable neuroanatomical regeneration was evident for other brainstem regions having direct axonal projections to the caudal cord, including the locus ceruleus, subceruleus, and raphe nuclei. Scale bar, $50 \mu \mathrm{m}$. 

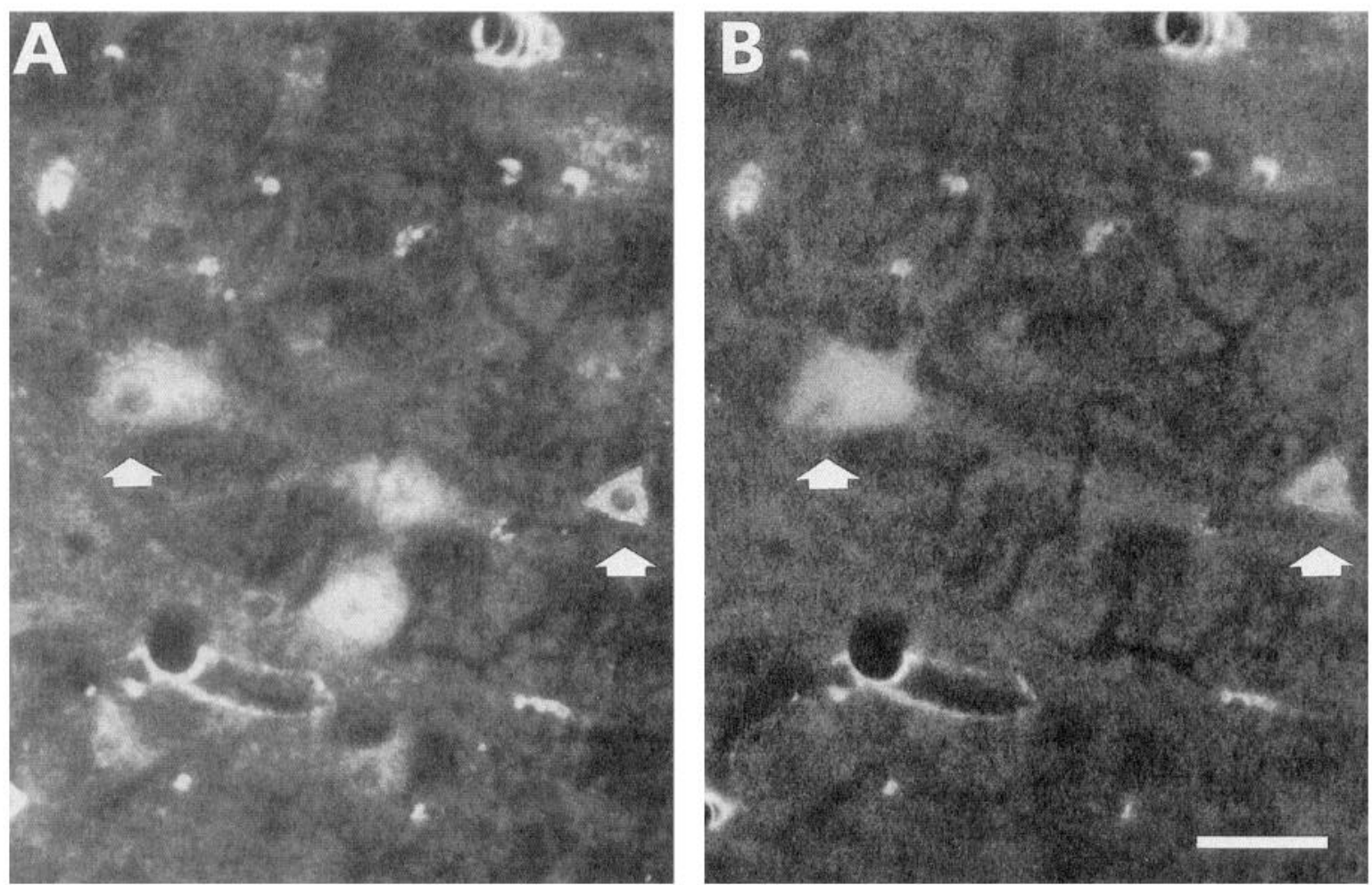

Figure 5. Evidence for true axonal regeneration following spinal cord transection and immunological myelin disruption in the hatchling chick. Photomicrographs of double-labeled reticulospinal neurons within the ventromedial reticular formation of the caudal pons. Brainstem-spinal neurons were labeled first by retrograde axonal transport of RDA injected into the low thoracic spinal cord on P6. The thoracic spinal cord was transected on P8. The infusion of serum complement with GalC antibodies into the adjacent cord was begun thereafter via an osmotic pump for the next 14 d. On P28, the second retrograde tracer, cascade blue-labeled dextran amine (CBDA), was injected into the low thoracic spinal cord and the animal was sacrificed $2 \mathrm{~d}$ later on P30. A, Gigantocellular reticulospinal neurons labeled prior to spinal transection with the first retrograde tracer, RDA. $B$, Gigantocellular reticulospinal neurons subsequently labeled with the second tracer, CBDA, after immunological myelin disruption and spinal transection. Note that some of the same brainstem-spinal neurons (arrows) are double-labeled with both RDA and CBDA. Scale bar, $50 \mu \mathrm{m}$.

\section{Discussion}

Our findings demonstrate that immunological myelin disruption within the hatchling chick (i.e., mature avian) spinal cord shortly after a thoracic transection facilitated partial neuroanatomical regeneration $(6-19 \%)$ of axotomized brainstem-spinal projections in vivo. Furthermore, this partial neuroanatomical regeneration was accompanied by functional synaptogenesis, such that focal electrical stimulation of a brainstem locomotor region in thoracic-transected, myelin disrupted chicks elicited alternating stepping activity. Transected animals that received intraspinal infusion of immunological control solutions (serum complement alone, GalC antibody alone, or PBS vehicle alone) showed no signs of myelin disruption, axonal regeneration or physiological recovery. These studies support and extend the available evidence that CNS myelin is inhibitory to the regeneration of injured CNS axons (Schwab et al., 1993; McKerracher et al., 1994; Mukhopadhyay et al., 1994). To our knowledge, however, this is the first demonstration that the disruption of myelin in a mature region of the CNS results in functional synaptogenesis by regenerating CNS axons.

Transient myelin disruption of the spinal cord was initiated by the direct intraspinal infusion of heterologous serum complement proteins plus a myelin/oligodendrocyte-specific, complement-binding antibody. The immunological myelin disruption protocol that we utilized appears to: (1) cause severe structural alteration of myelin, (2) have a rapid onset (within $24 \mathrm{hr}$ ), (3) persist for a few days beyond the duration of infusion (longest treatment period to date is $14 \mathrm{~d}$ ), (4) depend on complementmediated damage to myelin membranes, and (5) result in subsequent myelin repair within the region of myelin disruption (beginning within $7 \mathrm{~d}$ of the cessation of infusion).

None of the immunological control infusions produced spinal cord myelin disruption, indicating that both serum complement proteins and myelin/oligodendrocyte-specific, complement-binding antibodies are necessary for immunological myelin disruption. Similar immunological methods have been previously used to: (1) suppress myelin development in vitro (Dubois-Dalq et al., 1970; Fry et al., 1974; Hruby et al., 1977; Dorfman et al., 1979; Dyer and Benjamins, 1990), (2) suppress myelin development in vivo (Keirstead et al., 1992; Rosenbluth et al., 1994), and (3) reversibly alter CNS myelin stucture in vivo (guinea pig optic nerve: Sergott et al., 1984; Ozawa et al., 1989; cat optic nerve: Carroll et al., 1984; Carroll et al., 1985; rat spinal cord: Mastaglia et al., 1989).

The antibody-mediated, complement dependent nature of immunological myelin disruption may account for its rapid onset. Within minutes of treatment, complement fixation by cell-surface binding antibodies has been shown to compromise the ionic homeostasis of many different cells in vitro (Mayer, 1972; Morgan, 1989). GalC-mediated, complement-dependent myelin disruption in the guinea pig optic nerve in vivo (Sergott et al., 1984) was also detected within 1-2 hr of treatment. Due to the high concentration of GalC antigen within myelin membranes, and the observed "unravelling" nature of myelin disruption, we sug- 


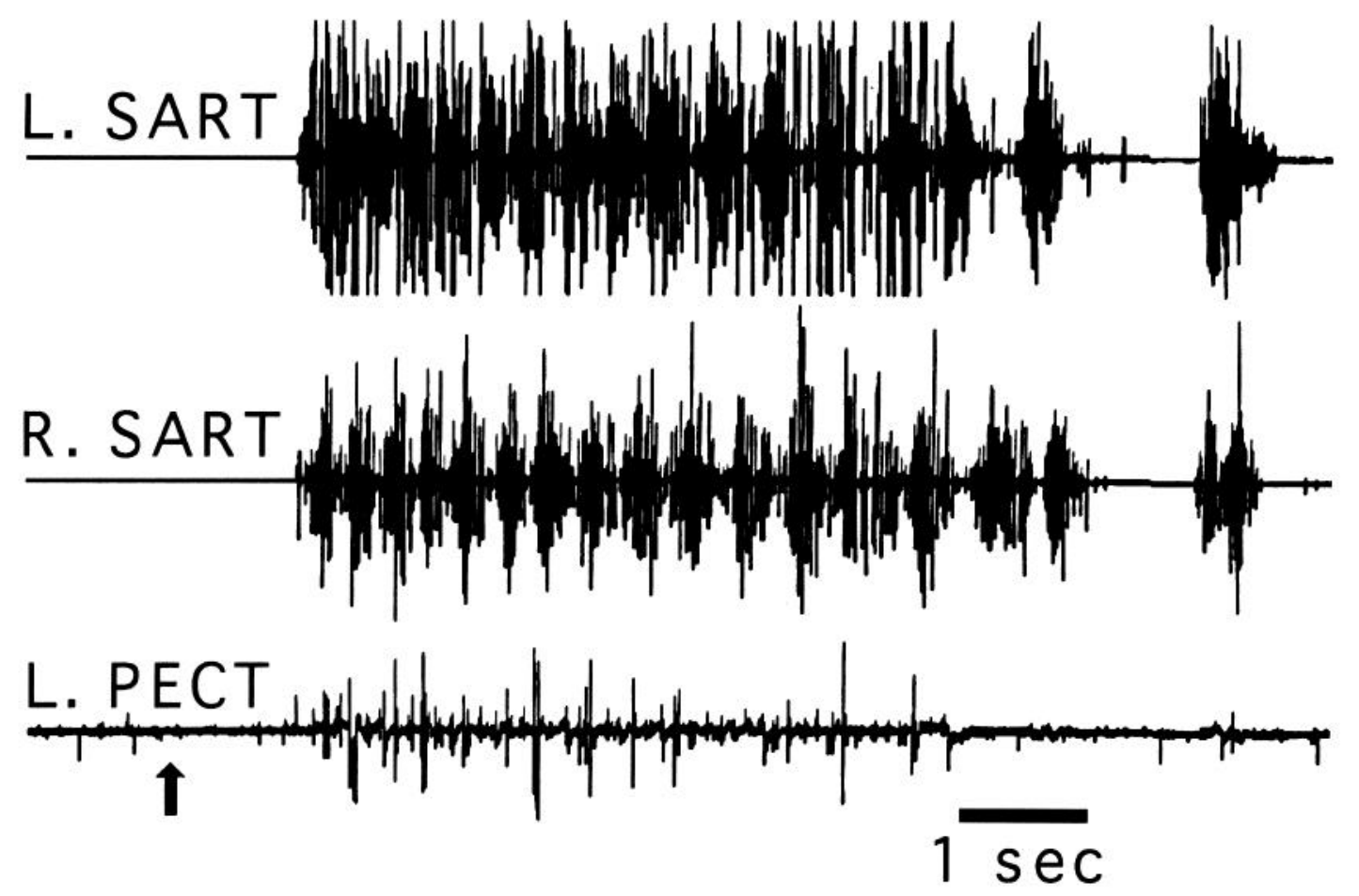

Figure 6. Focal electrical stimulation of a brainstem locomotor region evoked alternating stepping activity in a P27 chick $18 \mathrm{~d}$ after thoracic transection and immunological myelin disruption. Electromyographic (EMG) recordings are from the left and right sartorius (SART; major hip flexor) and right pectoralis (PECT; major wing depressor) muscles. Brainstem stimulation at $50 \mu \mathrm{A}$ (upward arrow indicates stimulus onset) evoked motor activity in both the wings and legs. In this trial, the wings were held to prevent movement artifacts from appearing in the leg EMG records.

gest that the GalC-mediated myelin disruption results from an antibody-directed attack of complement against myelin membranes. GalC is expressed by oliogodendrocyte cell bodies as well as myelin membranes (Ranscht et al., 1982); however, oligodendrocytes have also been observed to survive serum complement attack of oligodendrocyte membranes in vitro (Scolding et al., 1989).

Ultrastructural analysis (Fig. 1) and GalC immunostaining of myelin disrupted spinal cords confirmed that oligodendrocytes also survive the present immunological protocol (Fig. 3). The rapid onset of myelin recovery following immunological myelin disruption is also consistent with the survival of oligodendocytes. Recent Northern blot analysis of MBP gene expression in our laboratory has also indicated that oligodendrocytes survive the developmental suppression of myelination in the embryonic chick spinal cord (Keirstead et al., 1992, unpublished observations).

Immunological myelin disruption within the hatchling chick spinal cord differs considerably from the developmental suppression of myelin produced by a similar immunological protocol in the embryonic chick spinal cord. Intraspinal injection of serum complement proteins plus a myelin/oligodendrocytespecific, complement-binding antibody into the embryonic cord prior to myelin formation results in a delay of the developmental onset of myelination (Keirstead et al., 1992). In vitro studies indicate that GalC antisera cause an influx of extracellular calcium when applied to ramified oligodendrocytes in culture, resulting in disassembly of microtubules and a concomitant retraction of oligodendrocyte processes (Dyer and Benjamins, 1990). The subsequent removal of GalC antisera then results in reextension of oligodendrocyte processes from the surviving cell bodies. It is likely that the complete suppression of in vivo my- elin development in the embryonic chick is the result of a directed immunological attack against differentiating oligodendrocytes and their newly forming processes. Due to the high concentration of $\mathrm{GalC}$ in mature myelin membranes, we hypothesize that complement-mediated immunological attack in the hatchling chick spinal cord is directed to the myelin lamellae, resulting in the observed alterations of myelin structure described here. The "unravelling" of myelin lamellae has also been reported in the rat spinal cord following implantation of anti-GalC hybridoma cells (Rosenbluth et al., 1992).

The alterations of myelin structure revealed by ultrastructural analysis were accompanied by a loss of immunoreactivity for MBP (Figs. 1, 2). We have also observed a loss of MAG and PLP immunoreactivity in immunologically treated spinal cords. This indicates that a lack of immunoreactivity for myelin markers does not necessarily indicate a loss of myelin. It is also conceivable that the loss of MBP immunoreactivity following myelin disruption was a result of excess GalC or 04 antibodies "coating" the myelin membranes, effectively masking other epitopes. This is unlikely, however, as GalC immunoreactivity was present within myelin disrupted tissue and MBP is an internal myelin membrane antigen. It is perhaps more plausible that the gross alterations of myelin structure, as revealed by ultrastructural analysis, were accompanied by alterations in protein structure. Nevertheless, the presence or absence of specific myelin proteins within disrupted myelin should be confirmed with appropriate Western blot analysis.

The partial neuroanatomical regeneration and physiological recovery of brainstem-spinal projections following axotomy indicates that demyelination is not required to render the CNS extraneuronal environment permissive for axonal regeneration. Immunological myelin disruption may alter myelin proteins oth- 
er than MBP. Myelin-associated proteins that have been shown to inhibit axonal growth and regeneration (Schwab and Caroni, 1988; McKerracher, et al., 1994; Mukhopadhyay et al., 1994) may also be altered by immunological myelin disruption. We cannot, however, discount the possibility that immunological myelin disruption facilitates axonal regeneration indirectly by altering the expression or release of other cellular factors within the spinal cord.

The neuroanatomical regeneration of brainstem-spinal projections in transected, myelin disrupted hatchlings did not result in any overt behavioral signs of locomotor recovery. After spinal cord transection, all animals remained incapable of standing or supporting their own weight. It is known that adult birds supported on a treadmill are capable of locomotion, mediated by the intrinsic activity of neural networks confined to the lumbar spinal cord (Sholomenko and Steeves, 1987; Steeves et al., 1987). Although spontaneous alternating leg movements were often observed in the present study, this activity could have been initiated by either intrinsic spinal circuits or descending supraspinal projections. Our brainstem stimulation experiments demonstrated that at least some of the regenerating brainstem-spinal axons were capable of forming functional synapses with target spinal neurons, which could then be activated in a behaviorally appropriate manner (i.e., brainstem-evoked stepping). Although these physiological experiments provide unequivocal documentation that transient immunological myelin disruption facilitates at least some functional axonal regeneration, they do not allow us to determine whether the brainstem-evoked nerve and muscle activity within the lumbar cord is only due to direct synaptic connections onto lumbar locomotor interneurons and motoneurons or also via regenerating propriospinal projections from more rostral regions of the cord. After embryonic spinal cord transection, neurophysiological studies on regenerating brainstem-spinal projections indicated that both routes are evident (Sholomenko and Delaney, unpublished observations). The most likely reason for the lack of voluntary locomotion in transected, myelin disrupted hatchlings may have been the significant muscular atrophy that occurred over the approximately 3 week recovery period. We cautiously speculate that without the observed disuse atrophy, it is possible that the degree of CNS axonal regeneration and functional synaptogenesis observed in our experimental animals might have been sufficient for voluntary locomotion.

There are also some notable differences between birds and mammals regarding pathological tissue changes after spinal cord injuries. Following complete transection, the proximal and distal segments of the severed hatchling chick spinal cord remained intimately juxtaposed. Fifteen to $21 \mathrm{~d}$ after spinal cord transection, light microscopic analysis of sectioned spinal cords indicated a lack of cavity formation at the transection site and an absence of autofluorescent inflammatory infiltrates separating the proximal and distal segments (Keirstead et al., unpublished observations). In contrast, transection of mammalian spinal cord often results in cavity formation at the lesion site (Reier and Houle, 1988; Dusart and Schwab, 1994) that is associated with a robust inflammatory response. This difference does not appear to be due to the fused nature of the avian thoracolumbar vertebral column (i.e., lack of vertebral distraction), because spinal injury within unfused avian vertebrae (e.g., cervical cord) also shows no subsequent cavity formation (McBride and Steeves, unpublished observations). Thus, the secondary cell damage dif- ferences between birds and mammals may be due to species differences in the immune response to CNS injuries.

The degree of axonal regeneration and functional recovery differs significantly between myelin-suppressed chicks transected during late embryonic development (Keirstead et al., 1992) and the present study where animals were transected as hatchlings; an age in these precocial animals when the spinal cord and brainstem is adultlike in all known respects (Sholomenko et al., 1991; Steeves et al., 1994). It is most likely that developmental changes contribute to the differences in regeneration and in recovery. For example, the dramatic functional recovery noted in the myelin-suppressed, transected embryos may be due to: (1) an enhanced intrinsic ability for axonal growth in embryos, (2) differences in the abundance of adhesion molecules and growth factors, and/or (3) a relative paucity of growth-inhibitory factors. Although immunological myelin disruption in the hatchling chick severely alters the structure of myelin surrounding large and small diameter axons, some small diameter axons retain compacted myelin. Thus, functional myelin-associated proteins that inhibit neurite outgrowth could still exert some of their influence.

The available data from both classes of higher vertebrates (Schwab et al., 1993; McKerracher et al., 1994; Mukhopadhyay et al., 1994; Steeves et al., 1994) clearly suggest that myelin has a prominent role in determining the regenerative success of axotomized embryonic and adult CNS neurons. In the present study, only those animals subjected to transient myelin disruption after spinal cord transection showed signs of axonal regeneration and physiological recovery. Functional recovery has also been observed following spinal cord injury in species having an unmyelinated CNS such as the lamprey (McClellan, 1990; Lurie and Selzer, 1991). Consequently, the more robust functional CNS regeneration observed after injury in both immature birds and mammals may be due to embryonic neurons being relatively insensitive to glial-derived inhibitory molecules. This is also supported by the finding that undifferentiated embryonic neurons differentiate more robustly than adult neurons when grown on peripheral nerve substrates in vitro (Bedi et al., 1992) or within adult CNS (Schwab et al., 1993).

Finally, why has a system developed that prohibits regeneration following CNS injury? The inhibitory nature of CNS myelin for neurite outgrowth may have evolved for developmental reasons that incidently affect regenerating neurons. It is possible that the presence of myelin suppresses aberrant axon collateral sprouting in the mature CNS, thereby acting as a stabilizing influence on completed neural pathways. This hypothesis is supported by the ohservation that the developmental onset of CNS myelination for any CNS pathway in higher vertebrates only occurs after axonal outgrowth and target recognition have been accomplished. In the embryonic chicken, for example, the developmental onset of spinal cord myelination takes place on E13 (Bensted et al., 1957; Hartman et al., 1979; Macklin and Weill, 1985; Keirstead et al., 1992), after all descending and ascending projections have completed axonal development and functional synapse formation (Okado and Oppenheim, 1985; Hasan et al., 1991, 1993; O’Donovan et al., 1992).

\section{References}

Bedi KS, Winter J, Berry M, Cohen J (1992) ADult rat dorsal root ganglion neurons extend neurites on predegenerated bu not normal peripheral nerves in vitro. Eur J Neursci 4:193-200.

Bensted JPM, Dobbing J, Morgan RS, Reid RTW, Payling Wright G 
(1957) Neuroglial development and myelination in the spinal cord of the chick embryo. J Embryol Exp Morphol 5:428-437.

Carroll WM, Jennings AR, Mastiglia FL (1984) Experimental demyelinating optic neuropathy induced by intraneural injection of galactocerebroside antiserum. J Neurol Sci 65:125-135.

Carroll WM, Jennings AR, Mastiglia FL (1985) Immunocytochemical study of the glial cell response in antibody-mediated optic nerve demyelination. Neurosci Lett Suppl 19:S49.

Dorfman SH, Fry JM, Silberberg DH (1979) Antiserum induced demyelination inhibition in vitro without complement. Brain Res 177: 105-114.

Dubios-Dalcq M, Niedieck B, Buyse M (1970) Action of anti-cerebroside sera on myelinated tissue cultures. Pathol Eur 5:331-347.

Dusart I, Schwab ME (1994) Secondary cell death and the inflammatory reaction after dorsal hemisection of the rat spinal cord. Eur $J$ Neurosci 6:712-724.

Dyer CA, Benjamins JA (1990) Glycolipids and transmembrane signalling: antibodies to galactocerebroside cause an influx of calcium in oligodendrocytes. J Cell Biol 111:625-633.

Fry JM, Weissbarth S, Lehrer GM, Burnstein MB (1974) Cerebroside antibody inhihits sulfatide synthesis and myelination and demyelination in cord tissue cultures. Science 183:540-542.

Hartman BK, Agrawal HC, Kalmbaach S, Shearer WT (1979) A comparative study of the immunohistochemical localization of basic protein to myelin and oligodendrocytes in rat and chicken brain. J Comp Neurol 188:273-290.

Hasan SJ, Nelson BH, Valenzuela JI, Keirstead HS, Schull SE, Ethell DW, Steeves JD (1991) Functional repair of transected spinal cord in embryonic chick. Restor Neurol Neurosci 2:137-154.

Hasan SJ, Keirstead HS, Muir GD, Steeves JD (1993) Axonal regeneration contributes to repair of injured brainstem-spinal neurons in embryonic chick. J Neurosci 13:492-507.

Heimer L, RoBards, MJ (1981) Neuroanatomical tract-tracing methods. New York: Plenum.

Hruby S, Alroul EC, Seil FJ (1977) Synthetic galactocerebroside evoke myelination-inhibiting antibodies. Science 195:173-175.

Keirstead HS, Hasan SJ, Muir GD, Steeves JD (1992) Suppression of the onset of myelination extends the permissive period for the functional repair of embryonic spinal cord. Proc Natl Acad Sci USA 89: 11664-11668.

Lurie DI, Selzer ME (1991) Axonal regneration in the adult lamprey spinal cord. J Comp Neurol 306:409-416.

Macklin WB, Weill CL (1985) Appearance of myelin proteins during development in the chick central nervous system. Dev Neurosci $7: 170-178$.

Mastaglia FL, Carrol WM, Jennings AR (1989) Spinal cord lesions induced by antigalactocerebroside serum. Clin Exp Neurol 26:33-44.

Mayer MM (1972) Mechanism of cytolysis by complement. Proc Natl Acad Sci USA 69:2954-2958.

McClellan AD (1990) Locomotor recovery in spinal-transected lamprey: role of functional regeneration of descending axons from brainstem locomotor command neurons. Neuroscience 37:781-798.

McKerracher L, David S, Jackson DL, Kottis V, Dunn RJ, Braun PE (1994) Identification of myelin-associated glycoprotein as a major myelin-derived inhibitor of neurite growth. Neuron 13: in press.

Morgan BP (1989) Complement membrane attack on nucleated cells: resistance, recovery and non-lethal effects. Biochem J 264:1-14.
Mukhopadhyay G, Doherty P, Walsh FS, Crocker PR and Filbin M (1994) A novel role for myelin-associated glycoprotein as an inhibitor of axonal regeneration. Neuron 13:757-767.

O'Donovan M, Sernagor E, Sholomenko G, Ho S, Antal M, Yee W (1992) Development of spinal motor networks in the chick embryo. J Exp Zool 261:261-273.

Okado N and Oppenheim RW (1985) The onset and development of descending pathways to the spinal cord in chick embryo. J Comp Neurol 232:143-161.

Ozawa K, Saida T, Saida K, Nishitani H, Kameyama M (1989) In vivo CNS demyelination mediated by anti-galactocerebroside antibody. Acta Neuropathol (Berl) 77:621-628.

Ranscht B, Clapshaw PA, Price J, Noble M, Seifert W (1982) Development of oligodendrocytes and schwann cells studies with a monoclonal antibody against galactocerebroside. Proc Natl Acad Sci USA 79:2709-2713.

Reier PJ, Houle JD (1988) The glial scar: its bearing on axonal elongation and transplantation approaches to CNS repair. Adv Neurol 47: 87-138.

Rosenbluth J, Liu Z, Guo D, Schiff R (1992) Effect of anti-GalC on myelin formation. Soc Neurosci Abstr 18:608.5.

Rosenbluth J, Liu Z, Guo D, Schiff R (1994) Inhibition of CNS myelin development in vivo by implantation of anti-GalC hybridoma cells. J Neurocytol 23:699-707.

Schnell L, Schwab ME (1990) Axonal regeneration in the rat spinal cord produced by an antibody against myelin-associated neurite growth inhibitors. Nature 343:269-272.

Schwab ME, Caroni P (1988) Oligodendrocytes and CNS myelin are nonpermissive substrates for neurite growth and fibroblast spreading in vitro. J Ncurosci 8:2381-2393.

Schwab ME, Kapfhammer JP, Bandtlow CE (1993) Inhibitors of neurite growth. Annu Rev Neurosci 16:565-595.

Scolding MJ, Houston A, Morgan BP, Campbell AK, Compston DS (1989) Reversible injury of cultured rat oligodendrocytes by complement. Immunology 67:441-446.

Sergott RC, Brown MJ, Silberberg DH, Lisak RP (1984) Antigalactocerebroside serum demyelinates optic nerve in vivo. J Neurol Sci 64:297-303.

Shimizu I, Oppenheim RW, O'Brian M, Schneiderman A J (1990) Anatomical and functional recovery following spinal cord transection in the chick embryo. J Neurobiol 21:918-937.

Sholomenko GN, Steeves JD (1987) Effects of selective spinal cord lesions on hindlimb locomotion in birds. Exp Neurol 95:403-418.

Sholomenko GN, Funk GD, Steeves JD (1991) Locomotor activities in the decerebrate bird without phasic afferent input. Neuroscience 40:257-266.

Sommer I, Schachner M (1982) Cell that are 04 antigen-positive and 01 antigen-negative differentiate into 01 antigen-positive oligodendrocytes. Neurosci Lett 29:183-188.

Steeves JD, Sholomenko GN, Webster DMS (1987) Stimulation of the pontomedullary reticular formation initiates locomotion in decerebrate birds. Brain Res 401:205-212.

Steeves JD, Keirstead HS, Ethell DW, Hasan SJ, Muir GD, Pataky DM, McBride CB, Petrausch B, Zwimpfer TJ (1994) Permissive and restrictive periods for brainstem-spinal regeneration in the chick. Prog Brain Res 103:243-262.

Webster DM, Steeves JD (1988) Origins of brainstem-spinal projections in the duck and goose. J Comp Neurol 273:573-583. 